\title{
Model Identification of Continuous Fermentation under Noisy Measurements
}

\author{
Rudy Agustriyanto \\ Chemical Engineering Department, University of Surabaya, Jl. Raya Kalirungkut, Surabaya, Indonesia.
}

Received: 18 September 2014 / Accepted: 30 November 2014

\begin{abstract}
:
The dynamic model concept plays a central role in automatic control. Understanding the dynamic behavior of chemical and biological processes depends first on understanding the steady state behavior of these processes, then the dynamic characteristics of the process (e.g., the time constant, gain and deadtime) can be used to determine how long it takes to approach the new steady state and what path the process takes. The dynamic models can be used for bioprocess design, analysis of bioprocess control approaches, operator training, and start-up / shutdown strategy development. This paper will present bioprocess model identification of continuous fermentation for gluconic acid production under measurement noise. In this study, the input and output data was generated from first principle dynamic bioprocess model using Contois kinetic model and mass balances. Simulated measurement noises were then added to process variables. The data was then analyzed using System Identification Toolbox in Matlab. The final results obtained are in the form of Laplace-transfer functions.
\end{abstract}

Key words: Biology, chemical, dynamic, laplace, model, simulation

\section{Introduction}

Microbial fermentation is a process in which a population of micro-organism (bacteria, yeasts, moulds, etc) are grown using certain nutritive elements (nutrients) under favorable surrounding conditions (temperature, $\mathrm{pH}$, agitation, aeration, etc). It schematically corresponds to the transformation of subtances (generally carbonaceous substrates) into products, resulting from the metabolic activity of cells. The main components of the reaction are as follows:

- Substrates, denoted as S, which are necessary for the growth of micro-organism, or even which are precursors of a compound to be produced. These substrates generally contain a source of carbon (glucose etc) and sometimes nitrogen and phosphorus. - Microbial biomasses, denoted as X.

- End products, denoted as P.

From the view point of mathematical modeling, biological reactors can be divided into two major classes: stirred tank reactors (for which the reacting medium is homogenous and the reaction is described by ordinary differential equations), and reactors with a spatial concentration gradient (such as fixed beds, fluidized beds, air lifts, etc., for which the reaction is described by partial differential equations).

In the fermentation of glucose into gluconic acid, the overall reaction mechanism can be described as [1]:
Cell growth:

$$
\mathrm{C}_{6} \mathrm{H}_{12} \mathrm{O}_{6}+\text { biomass }+\mathrm{O}_{2} \rightarrow \text { biomass }
$$

Glucose oxidation:

$$
\mathrm{C}_{6} \mathrm{H}_{12} \mathrm{O}_{6}+\mathrm{O}_{2} \stackrel{\mathrm{GOD}}{\longrightarrow} \mathrm{C}_{6} \mathrm{H}_{10} \mathrm{O}_{6}+\mathrm{H}_{2} \mathrm{O}_{2}
$$

Gluconolactone hydrolysis:

$$
\mathrm{C}_{6} \mathrm{H}_{10} \mathrm{O}_{6}+\mathrm{H}_{2} \mathrm{O} \rightarrow \mathrm{C}_{6} \mathrm{H}_{12} \mathrm{O}_{7} \text { (GluconicAcid) }
$$

$\mathrm{H}_{2} \mathrm{O}_{2}$ decomposition:

$$
\mathrm{H}_{2} \mathrm{O}_{2} \stackrel{\text { catalysis }}{\longrightarrow} 2 \mathrm{H}_{2} \mathrm{O}+\mathrm{O}_{2}
$$

The cell growth model used in this research is Contois equation which can be written as follows:

$$
\mu=\mu_{m} \frac{S}{K_{S}^{\prime} X+S}
$$

Where:

$$
\begin{aligned}
& \mu=\text { specific growth rate, } 1 / \mathrm{h} \\
& X=\text { cell concentration, } \mathrm{g} / \mathrm{L} \\
& S=\text { substrate concentration, } \mathrm{g} / \mathrm{L} \\
& \mu_{m}=\text { maximum specific growth rate, } 1 / \mathrm{h} \\
& K_{S}^{\prime}=\text { Contois saturation constant }
\end{aligned}
$$

The Contois model describes cell inhibition on the growth which is suitable for fermentation with high cell density. In batch fermentation, the mass balance of the cell, substrate and product can be written as follows:

\footnotetext{
*Corresponding author: Rudy Agustriyanto,

E-mail: rudy.agustriyanto@staff.ubaya.ac.id
} 
$\frac{d X}{d t}=r_{X}=\mu X$

$\frac{d S}{d t}=r_{S}=\frac{1}{Y_{X / S}} \frac{d X}{d t}-\frac{1}{Y_{P / S}} \frac{d P}{d t}-m_{S} X$

$\frac{d P}{d t}=r_{P}=\alpha \frac{d X}{d t}+\beta X$

Where:

$Y_{X / S}=$ yield coefficient for cell on substrate

$Y_{P / S}=$ yield coefficient for product on substrate

$m_{S}=$ maintenance energy coefficient, $1 / \mathrm{h}$

$P=$ product concentration, $\mathrm{g} / \mathrm{L}$

$\alpha=$ growth associated product formation constant

$\beta=$ non-growth associated product formation constant, $1 / \mathrm{h}$

$t \quad=$ time, $\mathrm{h}$

$r_{X}=$ cell growth rate, $\mathrm{g} / \mathrm{L} . \mathrm{h}$

$r_{S}=$ substrate consumption rate, g/L.h

$r_{P}=$ product growth rate, $\mathrm{g} / \mathrm{L} . \mathrm{h}$

The experimental data from batch fermentation and used the data to determine the kinetic parameters by nonlinear least square curve fitting [2] as shown in Table 1.

Table 1. Contois kinetic parameters

\begin{tabular}{lcc}
\hline \multicolumn{1}{c}{ Kinetic Parameters } & Values \\
\hline Maximum specific growth rate, $\mu_{m}$ & $1.2698 \mathrm{~h}^{-1}$ \\
Contois saturation constant, $K_{S}^{\prime}$ & 99.9963 \\
& 0.1006 \\
Yield coefficient of cell, $Y_{X / S}$ & 0.5000 \\
Yield coefficient of product, $Y_{P / S}$ & $0.1097 \mathrm{~h}^{-1}$ \\
Maintenance coefficient, $m_{S}$ & $0.0068 \mathrm{~h}^{-1}$ \\
Growth associated product constant, $\alpha$ & $0.0001 \mathrm{~h}^{-}$ \\
Non growth associated product constant, $\beta$ & & \\
\hline
\end{tabular}

\section{Simulation}

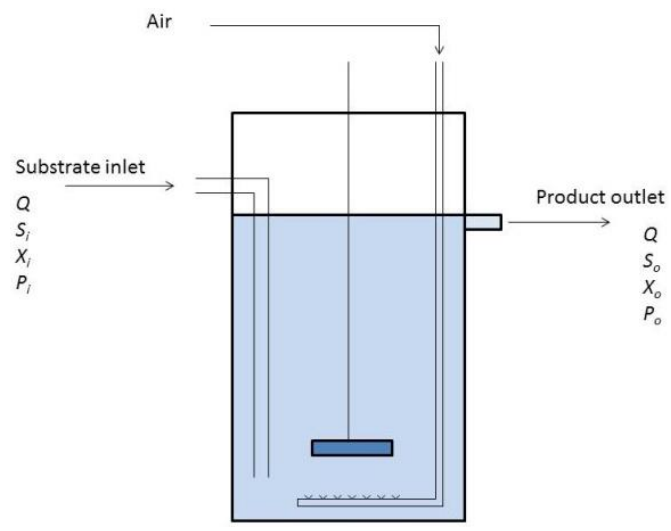

Figure 1. Schematic of continuous fermentation system.

Figure 1 shows the continuous fermentation system used in this study. In the system, feed with glucose concentration $S_{i}$ enters the fermenter at constant volumetric flowrate of $Q$. Gluconic acid will appear in product stream with concentration $P_{o}$ as a result of glucose fermentation of the cell (Aspergillus niger). The concentrations of the cell in the inlet and outlet of the fermenter are denotes as $X_{i}$ and $X_{o}$ respectively and the remaining glucose concentration at the fermenter outlet is $S_{o}$. At certain volumetric flowrate, the gluconic acid product concentration will depend on the volume of the fermenter. The condition of the fermenter shown in Figure 1 was to be kept constant at $\mathrm{pH}$ of 5.5 and the ratio of aeration rate to the fermenter volume of 1 .

Continuous fermentation as shown in Figure 1 can be modeled based on the mass balance equation of cell, substrate and product [2]. The models are as follows:

$$
\frac{d X}{d t} V=Q X_{i}+\frac{\mu_{m} S X}{K_{S}^{\prime} X+S} V-Q X
$$

$\left.\frac{d S}{d t} V=Q S_{i}-\left(\begin{array}{c}\frac{1}{Y_{X / S}} \frac{\mu_{m} S X}{K_{S}^{\prime} X+S}+m_{S} X+ \\ \frac{1}{Y_{P / S}}\left(\alpha \frac{\mu_{m} S X}{K_{S}^{\prime} X+S}+\beta X\right.\end{array}\right)\right) V-Q S_{O}$

$\frac{d P}{d t} V=Q P_{i}+\left(\alpha \frac{\mu_{m} S X}{K_{S}^{\prime} X+S}+\beta X\right) V-Q P$

And the steady state operating conditions of continuous fermentation system are shown in Table 2.

Table 2. Steady state operating conditions

\begin{tabular}{lrc}
\hline \multicolumn{1}{c}{ Operating Parameters } & \multicolumn{2}{c}{ Values } \\
\hline Hydraulic retention time, $R=V / Q$ & 24 & $\mathrm{~h}$ \\
Inlet cell concentration, $X_{i s s}$ & 0 & \\
Inlet substrate concentration, $S_{i s s}$ & 150 & $\mathrm{~g} / \mathrm{L}$ \\
Inlet product concentration, $P_{i s s}$ & 0 & \\
Outlet cell concentration, $X s s$ & 9.3843 & $\mathrm{~g} / \mathrm{L}$ \\
Outlet substrate concentration, $S_{s s}$ & 31.8372 & $\mathrm{~g} / \mathrm{L}$ \\
Outlet product concentration, $P_{s s}$ & 0.0863 & $\mathrm{~g} / \mathrm{L}$ \\
\hline
\end{tabular}

Although a first principle models are available for the continuous fermentation, here linear models are identified from the simulated bioprocess operation data using the nonlinear simulator. This is because in practical applications, bioprocess models are generally not available and have to be identified from bioprocess operation data. Step up and down tests at $\mathrm{t}=5$ hours and $\mathrm{t}=15$ hours were performed for input variables; and measurement noises were added to process outputs.

The complete transfer function expected is in the form [3]:

$$
y=G . u
$$


where:

$y=\left[\begin{array}{c}X \\ S \\ P\end{array}\right]$

$G=\left[\begin{array}{lll}G_{11} & G_{12} & G_{13} \\ G_{21} & G_{22} & G_{23} \\ G_{31} & G_{32} & G_{33}\end{array}\right]$

$u=\left[\begin{array}{c}X_{i} \\ S_{i} \\ P_{i}\end{array}\right]$

\section{Results and Discussion}

A series of step up and down were performed for all input variables of its nominal steady state at $t=5 \mathrm{~h}$ and $\mathrm{t}=15 \mathrm{~h}$. Process responses are sampled every 10 minutes and collected for $24 \mathrm{~h}$ simulation time from simulation based on the non-linear model provided in the form of differential equations. The complete identified transfer functions is as follows:

$$
G=\left[\begin{array}{ccc}
\frac{0.78288}{2.83535 s+1} & \frac{0.063909}{4.1056 s+1} & 0 \\
\frac{-0.684}{4.43432 s+1} & \frac{0.31143}{0.7449 s+1} & 0 \\
\frac{0.0011232}{7.13552 s+1} & \frac{0.00069252}{6.2320 s+1} & \frac{0.98646}{3.76835 s+1}
\end{array} \mid\right.
$$

Plots of actual responses and the simulated values using the identified models are shown in Figures 2 to 4. It can be seen from Figures 2 to 4 that the models are satisfactory in that the model simulated values (long range predictions) are very close to the actual process values.
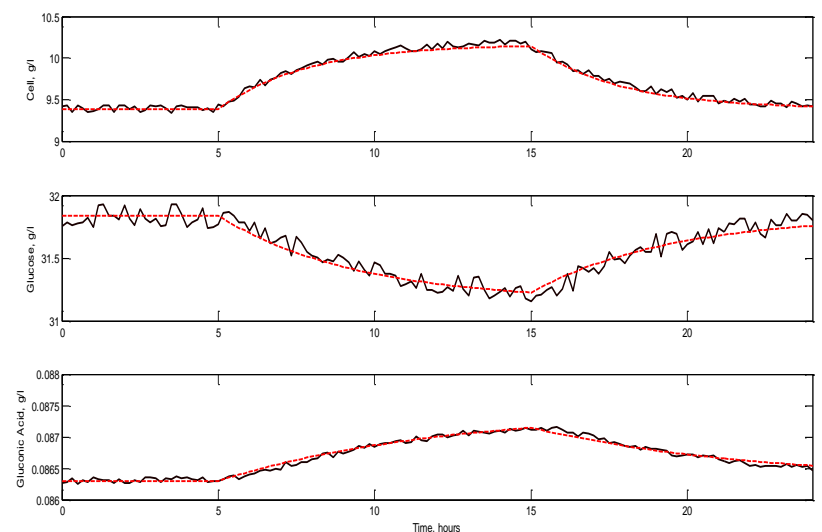

Figure 2. Actual process outputs and the simulated values from the identified model for a unit step up and down of inlet cell concentration at $\mathrm{t}=5$ and $\mathrm{t}=15$ hours. ( $\_$actual values, --predicted values).
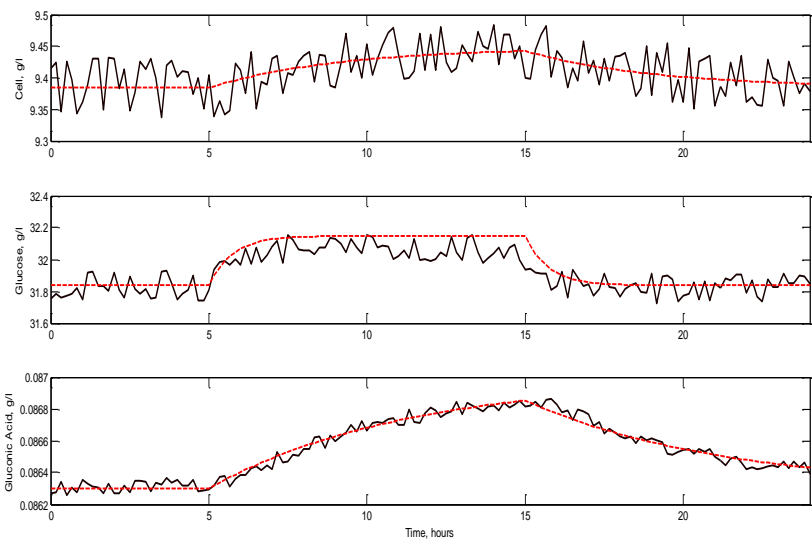

Figure 3. Actual process outputs and the simulated values from the identified model for a unit step up and down of inlet substrate concentration at $\mathrm{t}=5$ and $\mathrm{t}=15$ hours ( actual values, ---- predicted values).
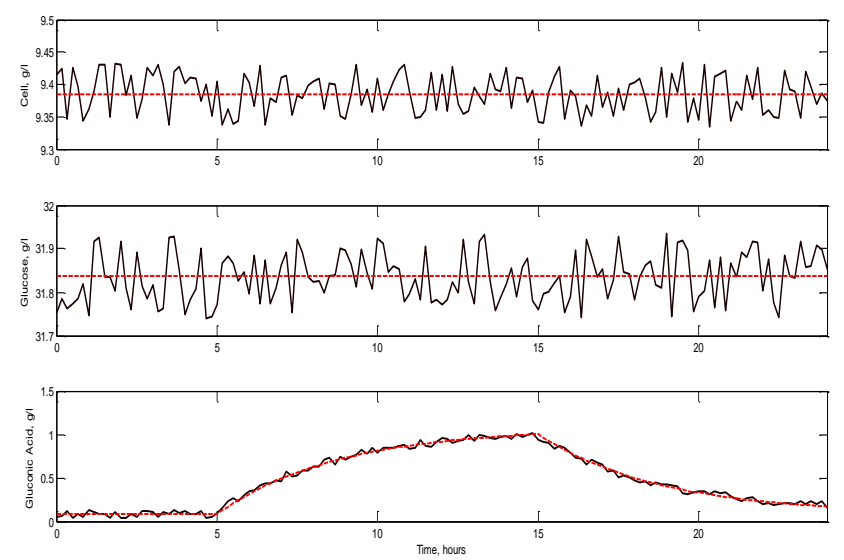

Figure 4. Actual process outputs and the simulated values from the identified model for a unit step up and down of inlet product concentration at $t=5$ and $t=15$ hours (_ actual values, ---- predicted values).

\section{Conclusions}

Model identification has been done for continuous fermentation of gluconic acid production using Aspergillus niger. The resulting models are in the form of Laplace transfer functions and able to give satisfactory prediction.

\section{Acknowledgement}

I thank the University of Surabaya for the research grant provided.

\section{References}

[1] H. Znad, J. Markoš, and V. Bales, Production of Gluconic Acid from Glucose by Aspergillus niger: Growth and NonGrowth Conditions, Process Biochemistry, 39, 2004, 13411345.

[2] A. Fatmawati, and R. Agustriyanto, Steady State and Dynamic of Gluconic Acid Production by Aspergillus niger, Journal of Chemistry and Chemical Engineering, 4(7), 2010, 39-45.

[3] L. Ljung, System Identification - Theory for the User, Prentice Hall, 1997. 